\title{
QUALIDADE DA ÁGUA UTILIZADA NA LIMPEZA DOS TANQUES DE GRANELIZAÇÃO DE LEITE CRU: IMPLANTAÇÃO E AVALIAÇÃO DA CLORAÇÃO DA ÁGUA PARA GARANTIA DA QUALIDADE DO PRODUTO
}

\section{Quality of water used in cleaning of bulk raw milk tanks: implementation and evaluation of water chlorination to ensure the product quality}

\author{
Joaquim Mário Neiva Lamas ${ }^{1}$, Maurilio Lopes Martins ${ }^{1 *}$, \\ Franklin Júnior Moreira da Silva ${ }^{l}$, Eliane Maurício Furtado Martins ${ }^{l}$, \\ Cristiano Amâncio Vieira Borges ${ }^{2}$, Marcelo Henrique Otênio ${ }^{2}$
}

\section{RESUMO}

A água, além de servir como bebida para os animais, é utilizada em atividades relacionadas à ordenha e armazenamento do leite. Assim, objetivou-se avaliar a influência da cloração da água utilizada em 18 propriedades localizadas na Zona da Mata do estado de Minas Gerais, sobre a contagem de células somáticas (CCS) e de bactérias totais (CBT) do leite cru. Amostras de água e de leite cru foram coletadas para análise, sendo as amostras de água coletadas das mangueiras utilizadas para lavagem dos tanques individuais e coletivos e as amostras de leite cru diretamente dos tanques de expansão. A cloração da água não influenciou seus parâmetros físico-químicos. Amostras cloradas de água apresentaram resultados positivos quanto à redução do Número Mais Provável de coliformes totais e termotolerantes, entretanto, não foi observada redução significativa $(\mathrm{p}>0,05)$ do número de bactérias heterotróficas. A composição do leite não foi alterada pela cloração da água e não houve redução significativa $(\mathrm{p}>0,05)$ das contagens de CCS e CBT devido à cloração. Portanto, mesmo a água utilizada na limpeza dos tanques não apresentando boa qualidade, estando em desconformidade com a legislação, esta não influenciou

1 Instituto Federal do Sudeste de Minas Gerais, Campus Rio Pomba, Av. Dr. José Sebastião da Paixão, s/nº, Bairro Lindo Vale, 36180-000, Rio Pomba, MG, Brasil. E-mail: maurilio.martins@ ifsudestemg.edu.br

2 Empresa Brasileira de Pesquisa Agropecuária (EMBRAPA) Gado de Leite, Juiz de Fora, MG, Brasil.

* Autor para correspondência. 
a qualidade do leite cru refrigerado, que apresenta muitas fontes de contaminação na região estudada.

Palavras-chave: tratamento de água; cloração; tanque de expansão; qualidade do leite.

\begin{abstract}
Water is the most important and indispensable resource to the maintenance of life in the Earth and it is not different in the farms, once it is a drink for the animals. Its use is also important in activities related to milking. The objective of this work was to evaluate the influence of chlorination of water used in 18 properties located in the Zona da Mata of Minas Gerais, Brazil, on the Somatic Cell Count (SCC) and Total Bacteria Count (TBC) of raw milk. Water samples were collected from hoses used for washing of individual and collective storage tanks of raw milk. In addition, samples of milk were collected for analysis. Chlorination of water did not influence their physicochemical parameters. Chlorinated water samples showed positive results in reducing the Most Probable Number of total and fecal coliforms, however, no significant reduction $(p>0.05)$ in their number of heterotrophic bacteria was observed. Milk composition was not affected by water chlorination and no significant reduction $(\mathrm{p}>0.05)$ counts of SCC and TBC due to chlorination was found. Therefore, even the water used in cleaning the tanks not presenting good quality, being in disagreement with the Brazilian law, this did not influence the quality of refrigerated raw milk, which has many sources of contamination in the studied region.
\end{abstract}

Keywords: water treatment; chlorination; expansion tank; quality of milk.

\section{INTRODUÇÃO}

A água é o recurso natural mais importante e indispensável à manutenção da vida no planeta. Nos estabelecimentos leiteiros ela assume grande importância, visto que, além de servir como bebida para os animais, seu uso também é fundamental em atividades relacionadas à ordenha (ROCHA et al., 2006; ELMOSLEMANY et al., 2009).

A água utilizada pelos estabelecimentos rurais é originada de minas, geralmente não protegidas, que por meio de bombas de recalque é conduzida às instalações para consumo. Ela também pode ser originada de poços escavados ou artesianos. Assim, verificar a origem da água, as condições na qual ela circula, tais como a natureza dos terrenos, canalizações e reservatórios, bem como os locais onde é consumida tornam-se importantes (ARAÚJO et al., 2013).

O modo de obtenção da água nas propriedades rurais promove a ocorrência de surtos de doenças veiculadas por ela, que na sua maioria podem ser consideravelmente reduzidos desde que a população tenha acesso à água potável. Infelizmente, um dos maiores problemas das fontes de abastecimento de água é a falta de um monitoramento sistemático de sua qualidade física, química e microbiológica (AMARAL et al., 2003; ARAÚJO et al., 2013).

No Brasil, a maior parte dos produtores de leite é classificada como pequenos ou médios e de caráter familiar (BRITO et al., 2004). O estado de Minas Gerais se consolida cada vez mais como maior produtor de leite entre as unidades da federação, por 
ter produzido, em 2010, cerca de $28 \%$ da produção nacional (IBGE, 2010). Das regiões do estado de Minas Gerais, a Zona da Mata se destaca na produção de leite (EMBRAPA, 2014). Porém, são poucos os investimentos nessa atividade, resultando em problemas em toda a cadeia produtiva, como baixa tecnificação, falta de controle sanitário dos animais e condições higiênicas inadequadas durante a ordenha, conservação e transporte do leite (SANTOS; FONSECA, 2007).

A qualidade da água usada para limpeza dos equipamentos de ordenha e no manejo é de grande importância para a obtenção de leite de boa qualidade que atenda aos padrões exigidos pela legislação. Portanto, deve-se ter um cuidado especial com a água utilizada na higienização dos equipamentos de ordenha, utensílios utilizados durante a mesma e dos tanques de expansão, que são os pontos críticos de maior importância para a contaminação do leite. É fundamental, portanto, que o produtor de leite conheça a qualidade da água tanto a utilizada na ordenha, quanto para o seu próprio consumo. Santos; Fonseca (2007) relataram que a qualidade microbiológica da água tem impacto direto sobre a qualidade do leite. Dessa forma, ela deve ser tratada para posterior utilização.

Mendonça et al. (2002) enfatizaram que na prática de controle microbiológico dos processos de obtenção do leite deve ser utilizada a cloração, um método seguro, de baixo custo e de fácil adoção nas propriedades leiteiras. A instalação de um cloro difusor nas caixas d'água pode contribuir com o melhoramento da qualidade do leite, pois a água sanitizada poderá melhorar as condições de higiene e limpeza dos utensílios da ordenha. Portanto, difusores de cloro são instrumentos que podem garantir a segurança de saúde e da produção de alimentos.

Assim, este trabalho buscou avaliar a qualidade da água utilizada na limpeza dos tanques de granelização de leite cru e implantar sistemas de cloração da água a fim de verificar sua influência na qualidade do produto armazenado em relação à contagem de células somáticas (CCS) e de bactérias totais (CBT).

\section{MATERIAL E MÉTODOS}

O estudo foi desenvolvido na comunidade de Bom Jardim pertencente à cidade de Rio Pomba que está localizada na Zona da Mata Mineira, microrregião da Mata de Ubá. Segundo a Prefeitura Municipal de Rio Pomba (2014), a região da pesquisa está situada em uma altitude que varia de 400 a $900 \mathrm{~m}$ acima do nível do mar. Sua população estimada em 2010 era de 17.110 habitantes e sua área de $252,418 \mathrm{~km}^{2}$.

O trabalho foi realizado em um período de 24 meses, com atividades de campo para localização dos produtores de leite na região, implantação de sistemas de cloração da água e operação e manutenção dos sistemas implantados. A água utilizada para lavagem dos equipamentos, utensílios, bem como dos tanques de armazenamento provinham de poços (produtor/tanque/amostra 2, 6, 7, 8, $10,13,14$ e 15 , totalizando $44 \%$ ) e nascentes (produtor/tanque/amostra 1, 3, 4, 5, 9, 11, 12, 16, 17 e 18, totalizando $56 \%$ ).

Também, durante dois anos, em doze repetições, foram coletadas amostras de $500 \mathrm{~mL}$ da água proveniente das mangueiras utilizadas para limpeza dos tanques de expansão individuais (produtor/ tanque/amostra 1, 6, 7, $8,10,12,13,14,16$ e 17 , totalizando $55,56 \%$ ) e coletivos (produtor/ tanque/amostra 2, 3, 4, $5,9,11,15$ e 18 , totalizando $44,44 \%$ ).

Os recipientes utilizados na coleta foram lavados, secos e, em seguida, adicionados de $0,1 \mathrm{~mL}$ de tiossulfato de sódio $\left(\mathrm{Na}_{2} \mathrm{~S}_{2} \mathrm{O}_{3}\right) 10 \%$ para cada $100 \mathrm{~mL}$ de água a ser coletada. Os frascos foram esterilizados a $121{ }^{\circ} \mathrm{C}$ por 15 minutos. A assepsia das mangueiras dos locais de coleta foi realizada com solução alcoólica 
$70 \%$, por meio de pulverização por dentro e por fora da mangueira. Posteriormente, a torneira foi aberta por três minutos e as amostras coletadas nas mangueiras utilizadas para a lavagem dos tanques de granelização. As amostras de água foram acondicionadas nos frascos estéreis e transportadas em caixas térmicas com temperatura inferior a $4{ }^{\circ} \mathrm{C}$ para os Laboratórios do Instituto Federal do Sudeste de Minas Gerais, campus Rio Pomba.

As amostras de leite cru refrigerado foram coletadas em frascos fornecidos pelo Laboratório de Qualidade do Leite (LQL) da Embrapa Gado de Leite de forma aleatória em seis tanques de expansão com capacidade de até $800 \mathrm{~L}$, de 800 a $1500 \mathrm{~L}$ e de mais de $1500 \mathrm{~L}$, num total de 18 tanques. Posteriormente, as amostras de leite foram transportadas em caixas térmicas com temperatura de $4{ }^{\circ} \mathrm{C}$ para o Laboratório que é integrante da Rede Brasileira de Laboratórios de Controle da Qualidade do Leite - RBQL para análise.

Dos 18 tanques de expansão considerados no estudo, nove foram aleatoriamente submetidos ao tratamento, e os outros nove submetidos ao controle experimental, sendo, em cada caso, três tanques de capacidade "baixa" (até $800 \mathrm{~L}$ ), três de capacidade "média" (1000 a 1500 L) e três de capacidade "alta" (2000 a $3000 \mathrm{~L})$.

Os tanques designados ao tratamento foram mantidos em condições normais de uso durante o primeiro ano do estudo (2012), e no segundo ano (2013) foram lavados/higienizados com água clorada, previamente ao despejo do leite para expansão. Os tanques designados ao controle foram mantidos em condições normais de uso em ambos os períodos de observação, i.e., não receberam água clorada em sua higienização em nenhum momento.

Em cada ano e para cada tanque, foram realizadas seis coletas espaçadas em aproximadamente 40 dias, dando origem, portanto, a um total de 12 observações por tanque.

\section{Caracterização físico-química e microbio- lógica da água procedente das mangueiras utilizadas para limpeza dos tanques de expansão}

As análises de $\mathrm{pH}$, dureza total, alcalinidade, cloro residual livre e cloretos foram realizadas de acordo com as metodologias estabelecidas por Andrade; Macêdo (1996). As análises de cor e turbidez foram realizadas conforme metodologias propostas pelo Standard Methods for the Examination of Water and Wastewater (RICE et al., 2012).

Para a determinação presuntiva de coliformes, $10 \mathrm{~mL}$ de cada amostra de água foram transferidos para 10 tubos de ensaio contendo $10 \mathrm{~mL}$ de caldo Lauril Sulfato de Sódio (LST) em concentração dupla e com tubo de Durhan, sendo incubados em estufa a $36^{\circ} \mathrm{C}$ por 48 horas. Posteriormente, o Número Mais Provável $(\mathrm{NMP} / \mathrm{mL})$ de coliformes totais na água foi determinado a partir da transferência de uma alçada dos tubos positivos em caldo LST para caldo verde brilhante (VB), incubados em estufa a $36{ }^{\circ} \mathrm{C}$ por 48 horas. Novamente, com auxilio de alça de repicagem, uma alíquota foi transferida dos tubos positivos em caldo LST para tubos contendo caldo Escherichia coli (caldo EC), que foram incubados em banho-maria com agitação a $45^{\circ} \mathrm{C}$ por 48 horas. Essa última etapa teve por objetivo a pesquisa de coliformes termotolerantes (RICE et al., 2012).

Para a contagem de bactérias heterotróficas, amostras de $10 \mathrm{~mL}$ de água foram diluídas em $90 \mathrm{~mL}$ de solução salina peptonada $(0,85 \% \mathrm{NaCl}$ e $0,1 \%$ de peptona $)$, de forma a se obter a diluição $10^{-1}$. Posteriormente, foram realizadas as diluições sucessivas até $10^{-3}$, sendo realizado, em seguida, o plaqueamento em profundidade em Agar Padrão para Contagem (PCA). As placas foram incubadas a $36{ }^{\circ} \mathrm{C}$ por 48 horas para a realização das contagens das colônias (MORTON, 2001). 


\section{Contagem de células somáticas, contagem bacteriana total e determinação dos com- ponentes do leite}

A contagem de células somáticas e de bactérias totais foram realizadas no Laboratório de Qualidade do Leite da Embrapa Gado de Leite de acordo com a metodologia de citometria de fluxo utilizando-se os equipamentos SomaCount FCM (Id.: 82015) e BactoCount IBC (Id.: 1109), de acordo com a IDF (1995). As análises relativas à composição centesimal do leite (extrato seco total e desengordurado, gordura, lactose e proteína), foram executadas por espectrometria de absorção no infravermelho médio, utilizando-se o equipamento Bentley FTS (Id.: 85015), de acordo com a IDF (1996).

\section{Análise estatística dos dados}

Para testar a hipótese de efeito significativo do tratamento - uso de água clorada na lavagem dos tanques de granelização sobre CCS, CBT, NMP de coliformes totais e NMP de coliformes termotolerantes, as médias destas variáveis para o ano de 2012 (ausência do tratamento) foram comparadas com as médias para o ano de 2013 (uso do cloro), para cada um dos nove tanques submetidos ao grupo do tratamento. De forma análoga, compararam-se também as médias das mesmas variáveis entre os anos de 2012 e 2013 para cada um dos outros nove tanques submetidos ao grupo controle do estudo.

Para as comparações, empregou-se o teste de Wilcoxon-Mann-Whitney para comparação de medianas (R Core Team, 2013), o equivalente não paramétrico ao tradicional teste $\mathrm{t}$ para amostras independentes na situação de grandes desvios da normalidade, como é o presente caso (variáveis são contagens, e os tamanhos amostrais estão reduzidos). Os testes foram realizados no software estatístico R (SHESKIN, 2004).
Nas comparações entre as médias para os tanques tratados, foram considerados testes unilaterais, i.e., estabelecidos para se testar a hipótese alternativa de redução da média, com a inclusão do cloro, contra a hipótese nula de igualdade entre as médias. Para os tanques não tratados do grupo controle, foram utilizados, como de costume, testes bilaterais, i.e., destinados a testar a hipótese alternativa de diferença entre as médias, seja para mais ou para menos, entre os anos de 2012 e 2013.

Em todas as comparações, foi considerado o nível de $5 \%$ de probabilidade $(\mathrm{p}<0,05)$ para alegação de significância de uma diferença.

\section{RESULTADOS E DISCUSSÃO}

\section{Qualidade físico-química das amostras de} água não cloradas

Constatou-se em 2012, que os valores de $\mathrm{pH}$ das amostras de água (Tabela 1) estavam de acordo com a legislação vigente (BRASIL, 2011a). João et al. (2011) analisaram 76 amostras de água de propriedades rurais do Meio Oeste Catarinense e também encontraram valores médios de $\mathrm{pH}$ e desvio-padrão de $6,80 \pm 0,70$, estando os resultados de acordo com os limites desejáveis de 6,0 a 9,0 estabelecidos para a água de consumo (BRASIL, 2011a).

Porém, em 2013, as amostras 2 e 11 apresentaram pH abaixo de 6,0 (Tabela 1). Com relação à turbidez, constatou-se que as amostras 4 e 7 (Tabela 1) estavam em desacordo com o padrão em 2012 e 2013 (BRASIL, 2011a). Além disso, foi observada forte coloração amarela destas amostras durante os períodos de chuva, sendo estas provenientes de nascente e poço, respectivamente. A legislação brasileira preconiza o máximo de 5 uT para turbidez da água (BRASIL, 2011a). Os altos valores de turbidez encontrados nestas amostras (Tabela 1) podem ser em 
função das nascentes não estarem devidamente encanadas.

Com relação à cor da água, foram encontrados resultados similares aos encontrados para a turbidez, ou seja, as amostras 4 e 7 apresentaram maiores índices de cor (Tabela 1). A cor aparente é um indicativo da presença de material suspenso e/ou dissolvido na água, o que não é recomendável para águas com fins de consumo humano e uso na indústria de alimentos devido à maior probabilidade de desenvolvimento de microrganismos e de presença de matéria orgânica e substâncias tóxicas.

A legislação vigente preconiza a obrigatoriedade da manutenção de, no mínimo, $0,2 \mathrm{mg} / \mathrm{L}$ de cloro residual livre ou $2 \mathrm{mg} / \mathrm{L}$ de cloro residual combinado ou de $0,2 \mathrm{mg} / \mathrm{L}$ de dióxido de cloro em toda a extensão do sistema de distribuição de água - reservatório e rede (BRASIL, 2011a). Assim, com relação ao cloro residual, constatou-se que todas as amostras, tanto em 2012 quanto em 2013, permaneceram abaixo do padrão mínimo estabelecido pela legislação para água potável, o que era esperado, visto se tratar de amostras de propriedades rurais que não realizavam tratamento da água.

Foi encontrado um alto índice de alcalinidade nas amostras 7 e 18 (Tabela 1). Aágua com elevada alcalinidade, ou seja, grande quantidade de carbonato de cálcio $\left(\mathrm{CaCO}_{3}\right)$ dissolvido aumenta a formação de precipitados e é capaz de neutralizar detergentes ácidos, exigindo maior concentração destes durante o procedimento de limpeza de equipamentos e superfícies. As amostras de água avaliadas neste estudo apresentaram alcalinidade na faixa de $\mathrm{pH}$ entre 4,4 e 8,4, sendo esta representada, portanto, apenas por bicarbonatos.

Quanto ao teor de cloreto, todas as amostras estiveram de acordo com o preconizado pela legislação, $250 \mathrm{mg} / \mathrm{L}$ (BRASIL, 2011a), sendo o maior índice encontrado na amostra 7 em 2012 (Tabela 1).
Todas as amostras de água não cloradas obtidas nos anos de 2012 e 2013 atenderam o preconizado pela legislação brasileira (BRASIL, 2011a) para o parâmetro dureza (Tabela 1). Quando a água é considerada pouco dura, dura ou muito dura, há uma diminuição significativa da eficiência da limpeza de equipamentos e utensílios utilizados na ordenha (GUERRA et al., 2011). As amostras 7 e 18 tiveram os maiores valores de dureza quando comparados com as demais. Estas amostras se enquadraram na classificação de dureza como água pouco dura $\left(\mathrm{CaCO}_{3}\right.$ entre $50 \mathrm{e}$ $100 \mathrm{mg} / \mathrm{L}$ ), sendo as outras amostras classificadas como água mole ou branda $\left(\mathrm{CaCO}_{3}<\right.$ $50 \mathrm{mg} / \mathrm{L})$ (Tabela 1).

\section{Qualidade microbiológica das amostras de água não cloradas}

Somente as amostras de água 6 e 11 não apresentaram coliformes termotolerantes em 2012 e 2013 (Tabela 1), o que correspondeu a $22 \%$ das amostras analisadas. Entretanto, elas possuíam coliformes totais (Tabela 1).

Todas as amostras de água não clorada analisadas no período de 2012 e 2013 apresentaram-se em desacordo com os padrões estabelecidos pela legislação vigente (BRASIL, 2011a) quanto aos parâmetros microbiológicos (Tabela 1), evidenciando a má qualidade desta água. Outros trabalhos conduzidos em diferentes regiões do país, bem como em outros países, retratam um quadro parecido com o encontrado neste estudo (RAPINI et al., 2003; RAMIRES et al., 2009).

Em relação à contagem padrão em placas de bactérias heterotróficas das amostras de água não tratadas com cloro nos anos de 2012 e 2013, constatou-se que somente as amostras 2, 6 e 11 (33\%) no ano de 2013, estavam de acordo com o padrão estabelecido pela legislação vigente (Figura 1A). Em outros estudos conduzidos em nosso país, a 


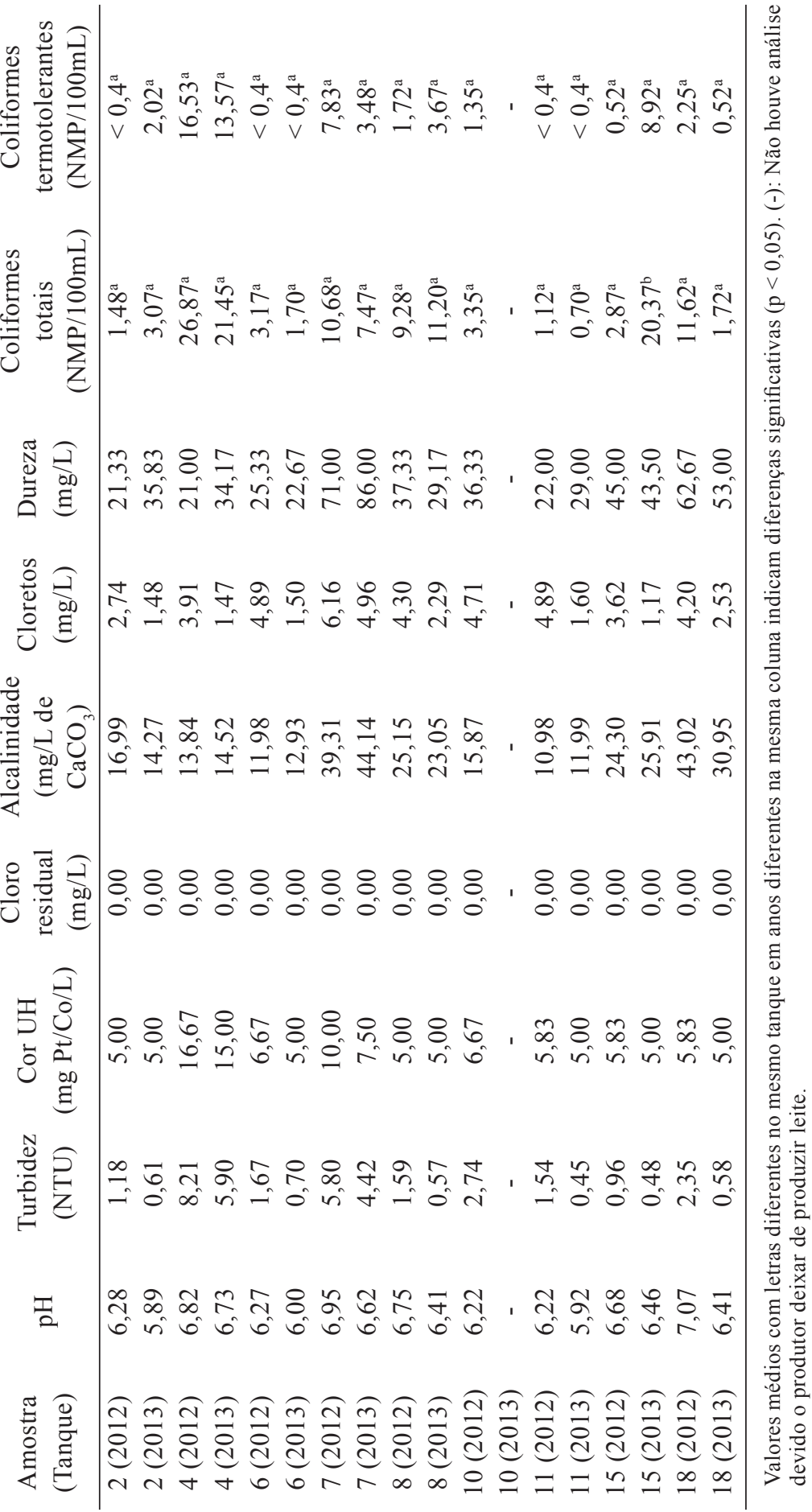


má qualidade da água utilizada em propriedades leiteiras é evidenciada (AMARAL et al., 2003; PICININ, 2003).

\section{Qualidade da água antes e após implanta- ção do sistema de cloração}

As amostras 1, 13 e 16 após a cloração apresentaram pH abaixo de 6,00 (Tabela 2), estando, portanto, em desacordo com o preconizando pela legislação (BRASIL, 2011a). Entretanto, ocorreram variações de pH mesmo nas amostras de água não cloradas citadas na Tabela 1. Constatou-se também que a amostra 5 apresentou $\mathrm{pH}$ baixo tanto em
2012 (sem cloração) quanto em 2013 (após a cloração).

Em relação à cor e a turbidez foi observado que todas as amostras (cloradas e não cloradas) se mantiveram de acordo com o preconizado pela legislação (Tabela 2). Com relação ao teor de cloro livre (Tabela 2), as amostras de água coletadas de fontes onde foram implantados os sistemas de cloração apresentaram valores de acordo com o exigido pela legislação (BRASIL, 2011a). Quanto à alcalinidade e cloretos (Tabela 2), todas as amostras (cloradas e não cloradas) atenderam à legislação vigente (BRASIL, 2011a).
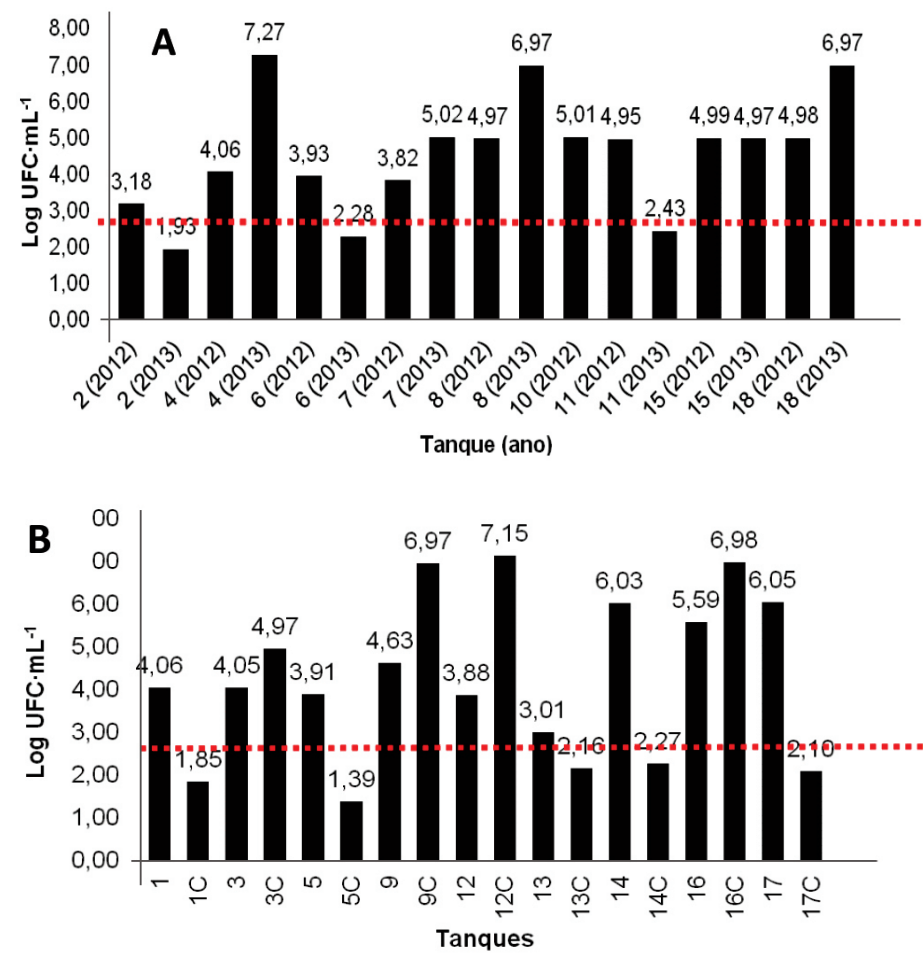

Figura 1 - Resultados médios da contagem padrão em placas de bactérias heterotróficas. A: valores obtidos das amostras de água não clorada nos anos de 2012 e 2013. B: Valores obtidos das amostras de água não clorada e clorada (número do tanque seguido da letra C). A linha tracejada indica o padrão de 2,7 Log UFC/mL estabelecido pela legislação (BRASIL, 2011a). 


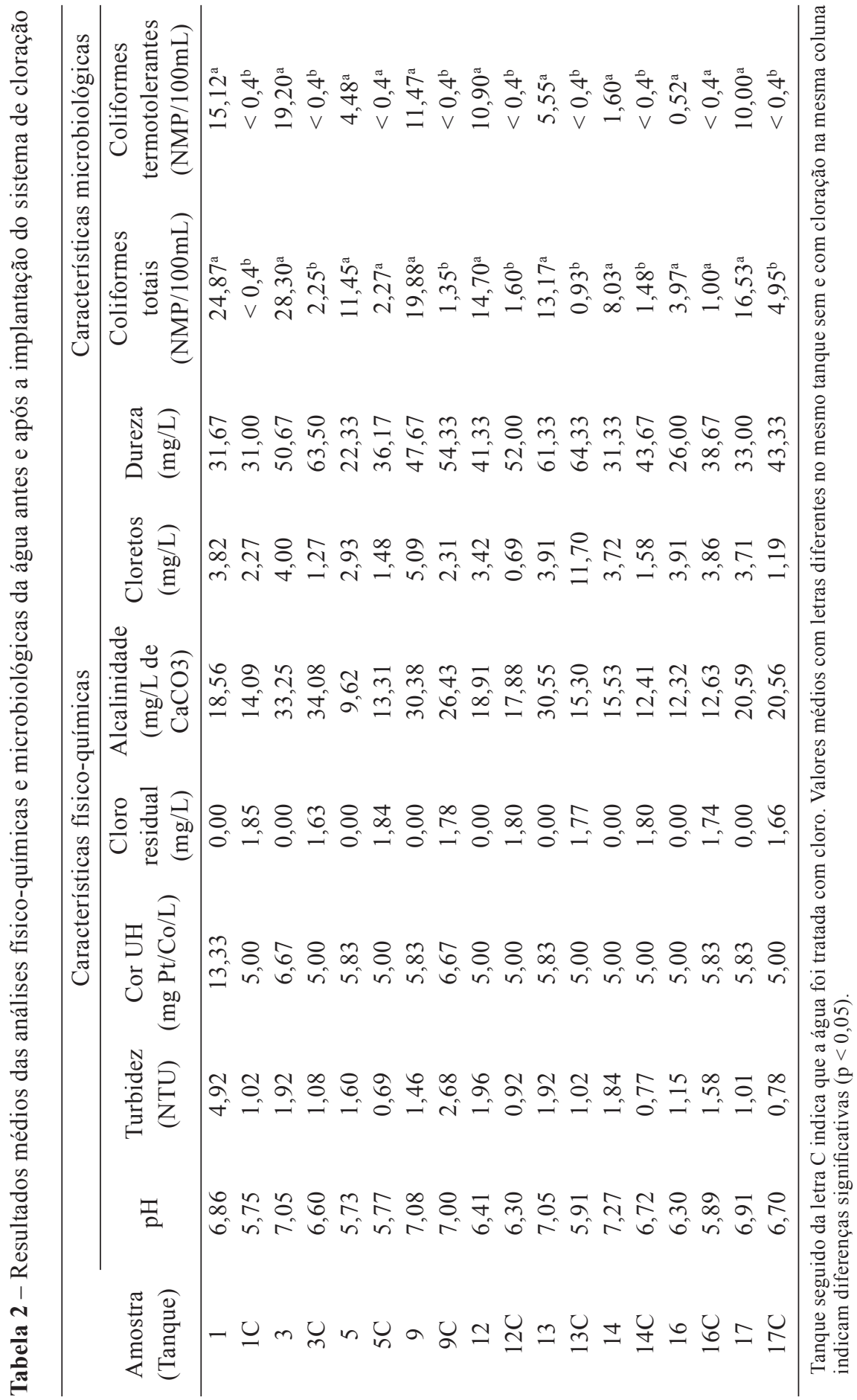


Dos 9 produtores de leite, onde os sistemas de cloração foram implantados, 4 apresentaram água com dureza moderada $\left(\mathrm{CaCO}_{3}\right.$ entre 50 e $150 \mathrm{mg} / \mathrm{L}$ ), sendo que em alguns a dureza da água aumentou após a implantação do sistema de cloração. Entretanto, em alguns produtores que não receberam a implantação do sistema de cloração também foi constatado aumento e/ou diminuição deste parâmetro na água (Tabela 1).

Todas as amostras de água após a cloração não apresentaram coliformes termotolerantes (Tabela 2). Constatou-se ainda que $78 \%$ das amostras apresentaram redução significativa $(\mathrm{p}<0,05)$ no NMP de coliformes totais após a cloração (Tabela 2). O cloro exerce ação antibacteriana por meio de oxidação irreversível de grupamentos sulfidrila de enzimas essenciais aos microrganismos, desativando funções metabólicas da célula bacteriana (SIQUEIRA et al., 2000).

Foi observado que das nove amostras avaliadas, $5(55,5 \%)$ apresentaram redução do número de bactérias heterotróficas (Figura 1B). Os valores médios de contagem de bactérias heterotróficas variaram de 1,39 log $\mathrm{UFC} / \mathrm{mL}$ a 7,15 $\log \mathrm{UFC} / \mathrm{mL}$ (Figura 1B). No trabalho de João et al. (2011), o resultado médio da contagem destas bactérias em amostras de água do meio Oeste Catarinense foi de $3,2 \pm 0,8 \log \mathrm{UFC} / \mathrm{mL}$, com valores variando de 0,7 a 5,4 $\log \mathrm{UFC} / \mathrm{mL}$.

Tabela 3 - Resultados médios de composição, de CCS e de CBT das amostras de leite obtidas de tanques lavados com água não clorada nos anos de 2012 e 2013

\begin{tabular}{cccccccc}
\hline \multirow{2}{*}{ Tanque } & \multicolumn{7}{c}{ Composição do Leite } \\
\cline { 2 - 7 } & $\begin{array}{c}\text { Gordura } \\
(\%)\end{array}$ & $\begin{array}{c}\text { Proteina } \\
(\%)\end{array}$ & $\begin{array}{c}\text { Lactose } \\
(\%)\end{array}$ & $\begin{array}{c}\text { EST } \\
(\%)\end{array}$ & $\begin{array}{c}\text { ESD } \\
(\%)\end{array}$ & $\begin{array}{c}\text { CCS } \\
(\mathrm{mil} / \mathrm{mL})\end{array}$ & $\begin{array}{c}\text { CBT } \\
(\mathrm{mil} / \mathrm{mL})\end{array}$ \\
\hline $2(2012)$ & 3,71 & 3,11 & 4,65 & 12,34 & 8,63 & $326,17^{\mathrm{a}}$ & $630^{\mathrm{a}}$ \\
$2(2013)$ & 3,66 & 3,04 & 4,52 & 12,08 & 8,42 & $354,33^{\mathrm{a}}$ & $910^{\mathrm{a}}$ \\
$4(2012)$ & 3,27 & 3,27 & 4,57 & 11,99 & 8,73 & $491,17^{\mathrm{a}}$ & $2000^{\mathrm{a}}$ \\
$4(2013)$ & 2,99 & 3,23 & 4,52 & 11,63 & 8,64 & $352,40^{\mathrm{a}}$ & $1400^{\mathrm{a}}$ \\
$6(2012)$ & 3,39 & 3,14 & 4,60 & 12,03 & 8,63 & $294,00^{\mathrm{a}}$ & $570^{\mathrm{a}}$ \\
$6(2013)$ & 3,24 & 3,02 & 4,60 & 11,72 & 8,48 & $147,00^{\mathrm{a}}$ & $820^{\mathrm{a}}$ \\
$7(2012)$ & 3,17 & 3,06 & 4,59 & 11,71 & 8,54 & $384,83^{\mathrm{a}}$ & $780^{\mathrm{a}}$ \\
$7(2013)$ & 3,37 & 3,22 & 4,52 & 11,99 & 8,62 & $533,00^{\mathrm{a}}$ & $900^{\mathrm{a}}$ \\
$8(2012)$ & 3,59 & 3,11 & 4,49 & 12,05 & 8,46 & $785,00^{\mathrm{a}}$ & $1700^{\mathrm{a}}$ \\
$8(2013)$ & 3,42 & 3,19 & 4,51 & 11,99 & 8,58 & $758,17^{\mathrm{a}}$ & $1900^{\mathrm{a}}$ \\
$10(2012)$ & 3,36 & 3,52 & 4,61 & 12,41 & 9,05 & $321,33^{\mathrm{a}}$ & $2400^{\mathrm{a}}$ \\
$10(2013)$ & - & - & - & - & - & - & - \\
$11(2012)$ & 3,40 & 3,09 & 4,53 & 11,91 & 8,51 & $483,00^{\mathrm{a}}$ & $750^{\mathrm{a}}$ \\
$11(2013)$ & 3,33 & 3,17 & 4,32 & 11,67 & 8,34 & $904,33^{\mathrm{a}}$ & $970^{\mathrm{a}}$ \\
$15(2012)$ & 3,20 & 3,08 & 4,39 & 11,53 & 8,34 & $445,67^{\mathrm{a}}$ & $950^{\mathrm{a}}$ \\
$15(2013)$ & 3,39 & 3,13 & 4,24 & 11,59 & 8,20 & $585,00^{\mathrm{b}}$ & $2600^{\mathrm{a}}$ \\
$18(2012)$ & 3,49 & 3,32 & 4,53 & 12,23 & 8,74 & $676,50^{\mathrm{a}}$ & $2000^{\mathrm{a}}$ \\
$18(2013)$ & 3,39 & 3,20 & 4,47 & 11,94 & 8,55 & $538,17^{\mathrm{a}}$ & $2700^{\mathrm{a}}$ \\
\hline
\end{tabular}

Valores médios com letras diferentes no mesmo tanque em anos diferentes na mesma coluna indicam diferenças significativas $(\mathrm{p}<0,05)$. (-): Não houve análise devido o produtor deixar de produzir leite. 
Destaca-se que todas as amostras de água dos tanques que apresentavam aumento das contagens já se encontravam em desacordo com o padrão estabelecido pela legislação antes da cloração (BRASIL, 2011a). Além disso, todas as amostras de água que apresentaram aumento da contagem padrão de bactérias heterotróficas provinham de nascentes, sendo que a qualidade das águas obtidas desta forma é muito instável, pois, muitas vezes, essas águas não são devidamente protegidas ao longo de seu trajeto até o local de armazenamento. Para minimizar este problema, faz-se necessária a implantação de sistema de filtração antes da etapa de cloração nas caixas d'água.

\section{Qualidade do leite cru armazenado em tanques antes e após a implantação do sistema de cloração da água de lavagem}

Na Tabela 3 são apresentados os resultados de composição do leite armazenado em tanques lavados com água não clorada nos anos de 2012 e 2013, não sendo observada diferença significativa $(\mathrm{p}>0,05)$ entre as amostras.

$\mathrm{Na}$ Tabela 4 são apresentados os resultados de composição média do leite armazenado em tanques lavados com água tratada e não tratada com cloro, também não foi observada diferença significativa $(\mathrm{p}>0,05)$ entre as amostras.

Tabela 4 - Resultados médios de composição, de CCS e CBT das amostras de leite obtidas de tanques lavados com água não tratada e tratada com cloro

\begin{tabular}{cccccccc}
\hline \multirow{2}{*}{ Tanque } & \multicolumn{7}{c}{ Composição do Leite } \\
\cline { 2 - 7 } & $\begin{array}{c}\text { Gordura } \\
(\%)\end{array}$ & $\begin{array}{c}\text { Proteina } \\
(\%)\end{array}$ & $\begin{array}{c}\text { Lactose } \\
(\%)\end{array}$ & $\begin{array}{c}\text { EST } \\
(\%)\end{array}$ & $\begin{array}{c}\text { ESD } \\
(\%)\end{array}$ & $\begin{array}{c}\text { CCS } \\
(\mathrm{mil} / \mathrm{mL})\end{array}$ & $\begin{array}{c}\text { CBT } \\
(\mathrm{mil} / \mathrm{mL})\end{array}$ \\
\hline 1 & 3,13 & 3,18 & 4,53 & 11,70 & 8,57 & $348,50^{\mathrm{a}}$ & $2800^{\mathrm{a}}$ \\
$1 \mathrm{C}$ & 3,07 & 3,22 & 4,51 & 11,68 & 8,61 & $247,33^{\mathrm{a}}$ & $1400^{\mathrm{a}}$ \\
3 & 3,07 & 3,15 & 4,69 & 11,80 & 8,73 & $298,33^{\mathrm{a}}$ & $1100^{\mathrm{a}}$ \\
$3 \mathrm{C}$ & 3,32 & 3,12 & 4,68 & 12,00 & 8,68 & $230,00^{\mathrm{a}}$ & $360^{\mathrm{b}}$ \\
5 & 3,64 & 3,37 & 4,59 & 12,51 & 8,88 & $621,17^{\mathrm{a}}$ & $1900^{\mathrm{a}}$ \\
$5 \mathrm{C}$ & 3,65 & 3,33 & 4,45 & 12,32 & 8,67 & $889,17^{\mathrm{a}}$ & $1700^{\mathrm{a}}$ \\
9 & 3,96 & 3,24 & 4,58 & 12,68 & 8,72 & $506,83^{\mathrm{a}}$ & $1700^{\mathrm{a}}$ \\
$9 \mathrm{C}$ & 3,84 & 3,15 & 4,46 & 12,33 & 8,49 & $576,83^{\mathrm{a}}$ & $2000^{\mathrm{a}}$ \\
12 & 3,19 & 3,01 & 4,52 & 11,61 & 8,42 & $221,17^{\mathrm{a}}$ & $1400^{\mathrm{a}}$ \\
$12 \mathrm{C}$ & 3,45 & 3,11 & 4,48 & 11,91 & 8,46 & $434,17^{\mathrm{a}}$ & $440^{\mathrm{b}}$ \\
13 & 3,35 & 3,34 & 4,61 & 12,24 & 8,89 & $391,17^{\mathrm{a}}$ & $620^{\mathrm{a}}$ \\
$13 \mathrm{C}$ & 3,97 & 3,16 & 4,49 & 1250 & 8,53 & $787,00^{\mathrm{a}}$ & $860^{\mathrm{a}}$ \\
14 & 3,68 & 3,44 & 4,56 & 12,59 & 8,91 & $734,83^{\mathrm{a}}$ & $2700^{\mathrm{a}}$ \\
$14 \mathrm{C}$ & 3,67 & 3,44 & 4,52 & 12,54 & 8,87 & $832,50^{\mathrm{a}}$ & $3300^{\mathrm{a}}$ \\
16 & 3,50 & 3,34 & 4,53 & 12,24 & 8,74 & $257,17^{\mathrm{a}}$ & $2400^{\mathrm{a}}$ \\
$16 \mathrm{C}$ & 3,52 & 3,29 & 4,48 & 12,16 & 8,64 & $512,33^{\mathrm{a}}$ & $4200^{\mathrm{a}}$ \\
17 & 3,61 & 326 & 4,49 & 12,23 & 8,63 & $639,67^{\mathrm{a}}$ & $1200^{\mathrm{a}}$ \\
$17 \mathrm{C}$ & 3,57 & 3,28 & 4,40 & 12,12 & 8,55 & $626,33^{\mathrm{a}}$ & $2400^{\mathrm{a}}$ \\
\hline
\end{tabular}

Tanques seguidos da letra $\mathrm{C}$ indicam que a água foi tratada com cloro. Valores médios com letras diferentes no mesmo tanque sem e com cloração na mesma coluna indicam diferenças significativas $(\mathrm{p}<0,05)$. 
As amostras de leite obtidas de tanques lavados e não lavados com água clorada mantiveram-se de acordo com as especificações estabelecidas pela legislação vigente quanto aos parâmetros de composição do leite (BRASIL, 2011b). Além disso, esses resultados demonstraram que a cloração da água de lavagem dos taques, equipamentos e utensílios de ordenha não influenciou a composição química do leite. A composição do leite geralmente é influenciada por fatores genéticos, ambientais, estágio de lactação, clima, manejo da alimentação, nutrição e incidência de doenças como mastite (RAMIRES et al., 2009).

A Instrução Normativa $n^{\circ} 62$ (BRASIL, 2011b) recomendava CCS e CBT de, no máximo, 600.000 por mililitro de leite até 30/06/2014 para a região sudeste do Brasil. Foi observado, nos tanques lavados com água não tratada comparando-se os anos de 2012 e 2013 (Tabela 3), que não houve redução significativa $(\mathrm{p}>0,05)$ nos valores médios de CCS e CBT para a maioria das amostras (94\%). Porém, a amostra 15 apresentou aumento significativo $(\mathrm{p}<0,05)$ na contagem de CCS de 2012 para 2013 (Tabela 3).

O aumento da CCS no leite ocorre devido à descamação do tecido mamário. A inflamação das células na glândula mamária faz com que estas sejam transportadas do sangue para o leite. Foi observado com relação à CCS que, das 17 amostras analisadas no período de 2012 e 2013, 76\% (Tabela 3) estiveram de acordo com a legislação vigente (BRASIL, 2011b).

Por outro lado, CBT é um indicador de qualidade higiênico sanitária e está relacionada às boas práticas de ordenha. Foi constatado neste trabalho (Tabela 3 ) que apenas a amostra 6 em 2012 estava de acordo com a legislação vigente (BRASIL, 2011b).

As variações encontradas para os valores de CBT estão relacionadas a fatores tais como higiene na ordenha, a origem/proce- dência do leite (rebanho, controle da mastite) assepsia dos ordenhadores, higienização dos equipamentos e utensílios de ordenha, condições de manejo e período de lactação. Brandão et al. (2013) avaliaram a qualidade do leite produzido na região de Rio PombaMG e verificaram imprudências durante o processo de recepção e armazenamento do leite cru refrigerado e relataram que a contaminação elevada pode estar associada com procedimentos de higienização inadequados no sistema de produção, nos tanques de granelização de leite cru, no armazenamento e no transporte.

Os resultados encontrados neste estudo para CCS e CBT estão de acordo com alguns autores. Ramires et al. (2009) concluíram que a qualidade microbiológica da água não influenciou a qualidade do leite, indicando que valores altos de CCS e CBT ocorreram por falhas na higienização no processo de obtenção do leite e dos equipamentos nas propriedades.

Da mesma forma, Perkins et al. (2009) avaliaram a qualidade da água de lavagem de 5421 fazendas em Ontario, Canadá, e concluíram que a água de lavagem possui pouca influência na qualidade final do leite cru. Entretanto, estes autores mencionam que se protocolos de qualidade do leite não estiverem sendo devidamente cumpridos, a água de lavagem de má qualidade pode ter um efeito significativo sobre a contagem bacteriana do leite. João et al. (2011) também relatam que a presença de contaminação bacteriana na água residual utilizada para enxágue dos equipamentos e diluição de produtos sanitizantes pode comprometer direta ou indiretamente a qualidade do leite produzido.

\section{CONCLUSÕES}

A água utilizada na limpeza dos tanques de granelização de leite cru não 
apresentou boa qualidade e conformidade com a legislação. A cloração da água foi eficiente para a redução de coliformes totais e termotolerantes, mas pouco influenciou a contagem de bactérias heterotróficas. Além disso, a cloração da água não influenciou a qualidade do leite cru granelizado, o que demonstra a diversidade de fontes de contaminação deste alimento na região estudada.

\section{AGRADECIMENTOS}

Os autores agradecem à Embrapa Gado de Leite, ao CNPq, à FAPEMIG e ao Grupo PET Ciências Agrárias do Instituto Federal do Sudeste de Minas Gerais - Campus Rio Pomba, pelo apoio financeiro.

\section{REFERÊNCIAS}

AMARAL, L. A. et al. Água de consumo humano como fator de risco à saúde em propriedades rurais. Revista Saúde Pública, v. 37, n. 4 , p. 510-514, 2003.

ANDRADE, N. J.; MACÊDO, J. A. B. Higienização na indústria de alimentos. São Paulo: Varela, 1996. 182p.

ARAUJO, C. F.; HiPÓlito, J. R.; WAICHMAN, A. V. Avaliação da qualidade da água de poço. Revista do Instituto Adolfo Lutz, v. 72, n. 1, p. 64-70, 2013.

BRANDÃO, V. I. et al. Qualidade do leite produzido no município de Rio Pomba, MG, com base em aspectos regulatórios. Perspectivas Online: Ciências Biológicas e da Saúde, v. 9, n. 3, p. 46-55, 2013.

BRASIL. Ministério da Saúde. Portaria $\mathrm{n}^{\circ} 2914$, de 12 de dezembro de 2011. Dispõe sobre os procedimentos de controle e de vigilância da qualidade da água para consumo humano e seu padrão de potabilidade. Diário Oficial da República Federativa do Brasil, Brasília, 14 dez. 2011a. Seção 1. p. 39-46.

BRASIL. Ministério da Agricultura Pecuária e Abastecimento. Instrução Normativa ${ }^{\circ} 62$, de 29 de dezembro de 2011. Regulamento Técnico de Identidade e Qualidade de Leite Cru Refrigerado, Regulamento Técnico de Identidade e Qualidade de Leite Pasteurizado e Regulamento Técnico da Coleta de Leite Cru Refrigerado e seu Transporte a Granel. Diário Oficial da República Federativa do Brasil, Brasília, 30 dez. 2011b. Seção 1.

BRITO, J. R. F. et al. Adoção de boas práticas agropecuárias em propriedades leiteiras da Região Sudeste do Brasil como um passo para a produção de leite seguro. Acta Scientiae Veterinariae, v. 32, n. 2, p. 125-131, 2004.

ELMOSLEMANY, A. M. et al. Risk factors for bacteriological quality of bulk tank milk in Prince Edward Island dairy herds. Part 1: Overall risk factors. Journal of Dairy Science, v. 92, n. 6, p. 2634-2643, 2009.

EMPRESA BRASILEIRA DE PESQUISA AGROPECUÁRIA (EMBRAPA). Embrapa gado de Leite. Estatísticas do leite. Disponível em: <http://www.cnpgl.embrapa.br>. Acesso em: 19 mar. 2014.

GUERRA, M. G. et al. Disponibilidade e qualidade da água na produção de leite. Acta Veterinaria Brasilica, v. 5, n. 3, p. 230-235, 2011.

INTERNATIONAL DAIRY FEDERATION. Milk. 148A: Enumeration of somatic cells. Brussels, 1995. $8 \mathrm{p}$.

INTERNATIONAL DAIRY FEDERATION. 141 B: Whole milk: Determination of milk fat, protein and lactose content-Guide for the operation of Mid-Infrared instruments. IDF Brussels, 1996. 
IBGE - Instituto Brasileiro de Geografia e Estatística. Produção da Pecuária Municipal. Disponível em: <http://www.ibge.gov. br/home/estatistica/economia/ppm/2010/ ppm2010.pdf $>$. Acesso em: 15 set. 2014.

JOÃO, J. H. et al. Qualidade da água utilizada na ordenha de propriedades leiteiras do Meio Oeste Catarinense, Brasil. Revista de Ciências Agroveterinárias, v. 10, n. 1, p. 9-15, 2011.

MENDONÇA, A. H. et al. Avaliação da qualidade da água e dos procedimentos de higienização de tanques de expansão e sua relação com a qualidade do leite cru resfriado. Revista do Instituto de Laticínios Cândido Tostes, v. 57, n. 327, p. 278-281, 2002.

MORTON, R. D. Aerobic plate count. In: DOWNES, F. P.; ITO, K. editors. Compendium of methods for the microbiological examination of foods. Washington $D C$ : American Public Health Association - APHA, 2001. p. 63-67.

PERKINS, N. R. et al. An analysis of the relationship between bulk tank milk quality and wash water quality on dairy farms in Ontario, Canada. Journal of Dairy Science, v. 92 , n. 8, p. 3714-3722, 2009.

PICININ, L. C. A qualidade do leite e da água de algumas propriedades leiteiras de Minas Gerais. 2003. 89p. Dissertação de (Mestrado em Tecnologia e Inspeção de Produtos de origem Animal) - Universidade Federal de Minas Gerais, Belo Horizonte, 2003.

PREFEITURA MUNICIPAL DE RIO POMBA. Dados demográficos. Disponível em: <http://www.riopomba.mg.gov.br/dadosdemograficos.php\#ancora>. Acesso em: 15 set. 2014 .
R CORE TEAM (2013). R: A language and environment for statistical computing. Vienna (Austria): R Foundation for Statistical Computing. Disponível em: <http://www.Rproject.org/>. Acesso em: 03 out. 2003.

RAMIRES, C. H.; BERGER, E. L.; ALMEIDA, R. Influência da qualidade microbiológica da água sobre a qualidade do leite. Archives of Veterinary Science, v. 14, n. 1, p. 36-42, 2009.

RAPINI, L. S. et al. Qualidade microbiológica da água de propriedades leiteiras na região metropolitana de Belo Horizonte - MG. Revista do Instituto de Laticínios Cândido Tostes, v. 58, p. 95-98, 2003.

RICE, E. W. et al. Standard Methods for the Examination of Water and Wastewater. 22 a ed. Washington: American Public Health Association - APHA, 2012.

ROCHA, C. M. B. M. et al. Avaliação da qualidade da água e percepção higiênicosanitária na área rural de Lavras, Minas Gerais, Brasil, 1999-2000. Caderno de Saúde Pública, v. 22, n. 9, p. 1967-1978, 2006.

SANTOS, M. V.; FONSECA, L. F. L. Estratégias para controle de mastite e melhoria da qualidade do leite. São Paulo: Manole, 2007. 314p.

SHESKIN, D. J. Handbook of parametric and nonparametric statistical procedures. $3^{\mathrm{a}}$ ed. Boca Raton (US): Chapman \& Hall/ CRC Press, 2004.

SIQUEIRA, J. F. J. et al. Chemomechanical reduction of the bacterial population in the root canal after instrumentation and irrigation with $1 \%, 2.5 \%$ and $5.25 \%$ sodium hypochlorite. Journal of Endodontics, v. 26, n. 6, p. 331-334, 2000. 